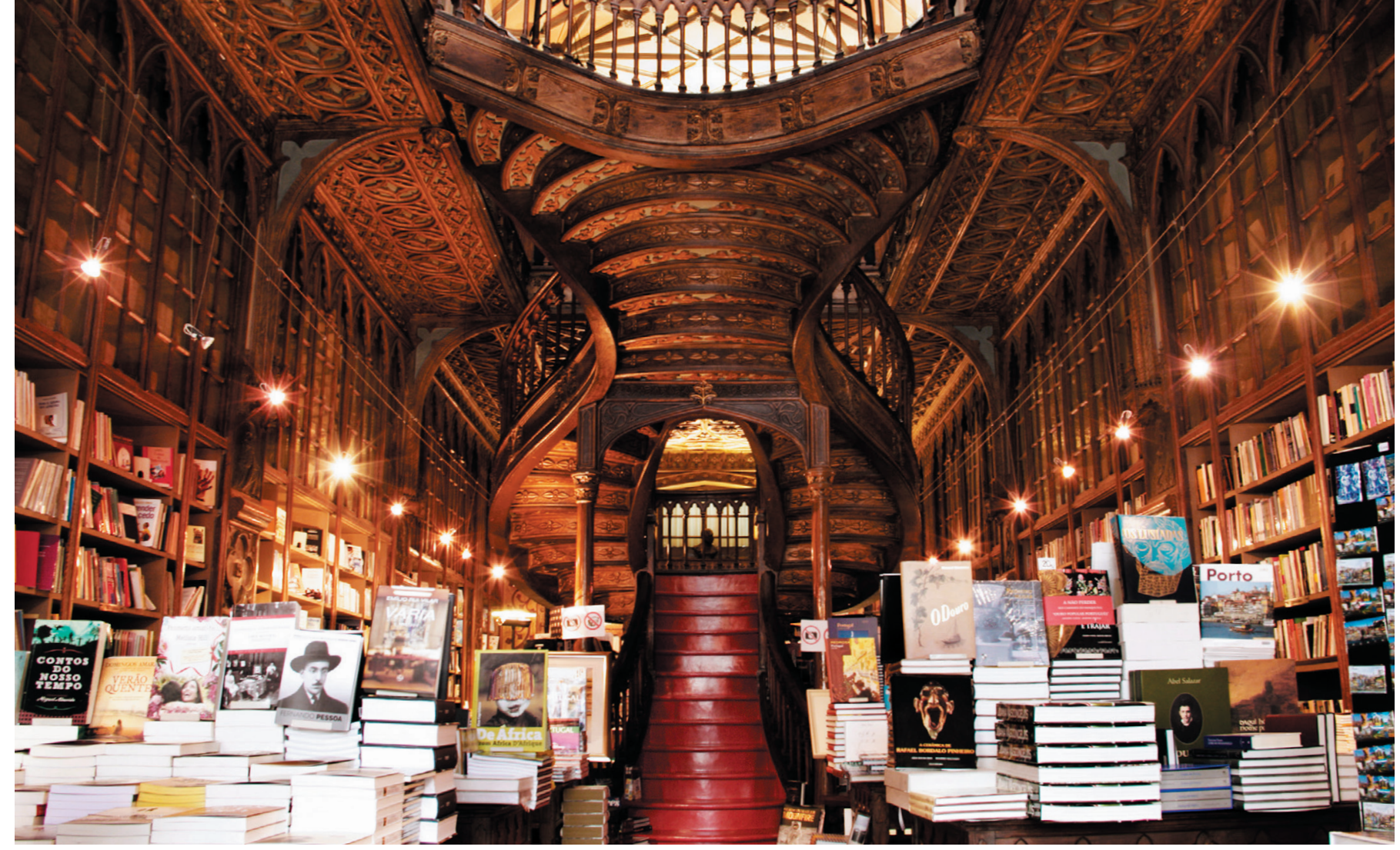

Which book will be a bestseller? Sales are often driven by word of mouth rather than quality.

\title{
SOCIAL NETWORKS
}

\section{The secrets of status}

\section{There are laws underlying success and fame. Mark Buchanan savours a study of them.}

$\mathrm{A}$ few years ago, physicist César Hidalgo and his team devised a way to rank the most famous people of all time. The criterion used for the Pantheon project was the number of languages a person's Wikipedia pages appear in. The most famous musician? Jimi Hendrix. The most famous American? Martin Luther King Jr. Perhaps inevitably, the classical Greek philosopher Aristotle heads the entire list.

Among celebrities, reality-television star Kim Kardashian comes 14th, although her fame clearly outweighs any recorded achievement. Such paradoxical mismatches of fame and attainments, as physicist and network scientist Albert-Lázló Barabási writes in The Formula, reflect deep social laws that can be understood through science. Success and recognition in many realms have only a tenuous link to effort, skill or inherent excellence. Often, they are determined by less obvious factors of human behaviour that influence how attention flows through social networks.

The Formula is a fun, fast, first-hand account of efforts to use big data to pull back the curtain on our collective dynamics. As Barabási shows, hidden statistical and multiplicative processes have huge consequences in the human world, yet often operate outside our general awareness.

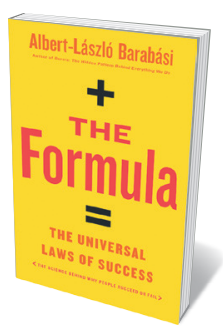

The Formula: The Universal Laws of Success

BARABÁSI
ALBERT-LÁSZLÓ

Little Brown (2018)

Many of the effects described wouldn't be surprising in a system of inanimate matter, such as cracks growing irregularly in a brittle material. It would just be ordinary statistical physics. But these unstable cascades are eye-opening when documented in systems of free-willed people, where they have major impacts on people's lives. They might propel one individual vastly beyond another of identical skill, or drive rapid, unpredictable transformations of social norms such as smoking.

Barabási describes how exploiting big data collected from the web, including social media and other digital repositories, is helping researchers to tease out how success and performance actually relate to one another. If one song is more popular, or one person more wealthy, is it because of inherent differences, or merely the result of luck and random amplification? Even 20 years ago, such questions were subject only to ideological debate, not scientific exploration. Science has changed the game.

Barabási considers puzzles in music, science, wealth, sports and wine. In some arenas, such as competitive tennis, skill and prowess are decisive. In others - including whether a book is pulped or becomes a bestseller - quality seems to be overwhelmed by network effects, such as the tendency to flock towards books that have already sold well. An intriguing example is German pilot Manfred von Richthofen (the 'Red Baron'). Remembered as one of the First World War's top flying aces, he was objectively outperformed on many counts by an almost-forgotten French counterpart, René Fonck. Von Richthofen's lasting celebrity arose, Barabási shows, in part from his early death as a war hero, which made him useful for propaganda.

How it works in general, Barabási suggests, is now becoming clear owing to the emergence from research of a number of simple "laws of success".

The first is that "performance drives success, but when performance can't be measured, networks drive success". With competitive tennis, better athletes win repeatedly, showing superiority. But when judging wine, it's not easy to find objective means of ranking: repeated blind tastings, even among wine experts, lead to wildly fluctuating outcomes. When quality is hard to measure, 
observed differences in success - judged by popularity or sales, for example - follow from network effects. People rush to buy an early leader, swayed by the mistaken belief that others' choices tell them about standard.

This results in huge differences in outcome that have nothing at all to do with quality. That phenomenon is the subject of the second law: "Performance is bounded, but success is unbounded." Take the top 100 wines entered into a competition. Their true differences in quality, for example in clarity or varietal character, are generally small: they're all produced by top winemakers using similar technology. Yet one wine, because of the amplifying power of social networks, might enjoy orders of magnitude more sales than others.

Social scientists have known about such effects for decades, although research by many, including Barabási and his students, has brought them into much clearer focus. The Formula also covers nuanced studies showing how success can be predicted. So the third law that Barabási describes is: "Previous success $\times$ fitness $=$ future success." Careful studies - for example, by network scientist Manuel Cebrian or complexity scholar Dashun Wang - have found that it's possible to identify how much of a product's popularity depends on its quality or fitness, and how much can be traced to random amplification by network effects. Detailed data on consumer ratings and sales over time gathered by a site such as Amazon.com can be used to disentangle herding effects (those tending to push the already popular towards further popularity) from real consumer preferences based on true perceived quality. This understanding can be used to forecast trends, but also to boost sales or consumer satisfaction.

And then there's the fourth law: "While team success requires diversity and balance, a single individual will receive credit for the group's achievements." Analyses of highly successful teams in science or business show that which individuals get the most credit has nothing to do with who actually did the work. Credit is based on perception, and is a collective social phenomenon. Effective teams absolutely require diversity, but society singles out lone individuals for the accolades.

Altogether, The Formula offers a rich tour of research on how relatively simple feedback forces channel our lives in surprising and counter-intuitive ways. We might think that success ought to be determined by a person's skill and hard work. Yet, more important is how other people respond, by interacting in complex social networks. Even individual success is a thoroughly social matter.

Mark Buchanan has written many books about network effects. He is based in Abergavenny, UK.

e-mail:buchanan.mark@gmail.com

\section{Books in brief}

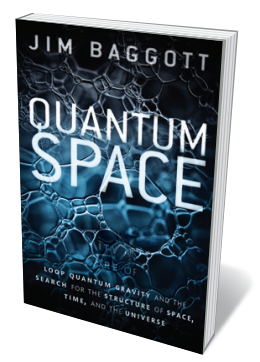

Quantum Space

Jim Baggott OXFORD UNIV. PRESS (2018)

Prolific physics writer Jim Baggott is back with a terrific page-turner on loop quantum gravity (LQG) — the theory posited as a solution to that chasm in physics between quantum mechanics and the general theory of relativity. Baggott digs into the how and why of what LQG might reveal about "space, time and the universe", tracing its evolution through the work of Abhay Ashtekar, Lee Smolin, Carlo Rovelli and others, to its current implications for, say, the physics of black holes. Baggott masterfully tenderizes the scientific chewiness and is careful not to over-egg what is, after all, a work in progress.

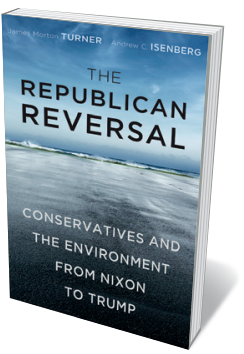

\section{The Republican Reversal}

James Morton Turner and Andrew C. Isenberg HARVARD UNIV. PRESS (2018) In the 1960s and 1970s, the US Republican Party - pressured by the era's environmental movement - created the Environmental Protection Agency (EPA) and extended the Clean Air Act. Today, it busily eviscerates the EPA while denouncing climate change as a hoax. Environmental historians James Turner and Andrew Isenberg follow this reversal from Ronald Reagan's presidency on, revealing how conservative ideologues hostile to science and bent on deregulation have gradually bolted US exceptionalism to anti-environmentalism. Searingly timely and cautiously hopeful.

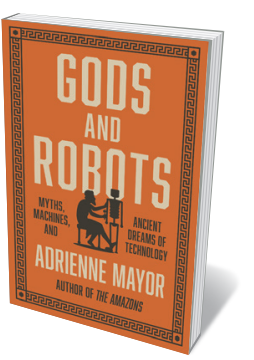

\section{Gods and Robots}

Adrienne Mayor PRINCETON UnIV. PRESS (2018)

More than two millennia before today's explosion in robot manufacture, bards and philosophers toyed with the concept of imitating life. Classics scholar Adrienne Mayor's astonishing chronicle harks back to mythic automata, such as "evil fembot" Pandora and bronze giant Talos. And she examines real mechanical devices - flying doves, bellowing statues and gliding Buddhas devised by virtuosic technicians from the Mediterranean to China. A third-century BC colossus crafted for Egyptian monarch Ptolemy II Philadelphus, for instance, could stand up, sit down and pour milk.

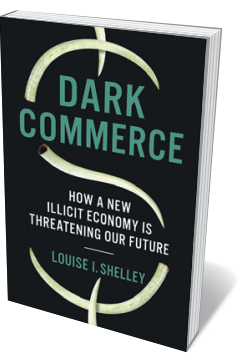

\section{Dark Commerce}

Louise I. Shelley PRINCETON UnIV. PRESS (2018)

Illicit trade in human organs, wildlife, arms and rare woods has vastly expanded over the past three decades as communications and digitization have improved apace. Here, Louise Shelley, a leading researcher in the field, examines organized crime over four millennia. She unpeels its disturbing dynamics today through case studies such as Silk Road, a vastly lucrative cybersupermarket, and the much-documented illegal market in rhino horn (currently priced at US $\$ 60,000$ per kilo). And she lucidly lays out the dark economy's planetary costs, as it escalates biodiversity loss and deforestation.

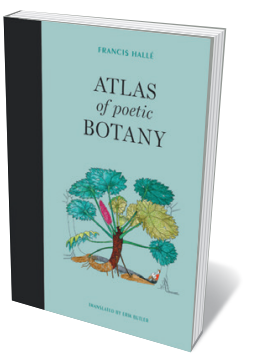

\section{Atlas of Poetic Botany}

Francis Hallé with Éliane Patriarca, transl. Erik Butler MIT PRESS (2018) From the epiphytic 'hanging' plant Guzmania lingulata to the mushroom mimic Helosis cayennensis, compelling oddities crowd equatorial forests. Botanist Francis Hallé celebrates their spectacular weirdness in this sprightly homage, translated from French by Erik Butler. Alongside descriptions of clonal forests, underground trees and 'dancing' plants, Hallé sets playful stylized drawings explicating the strange behaviours, adaptations and coevolution of each species. It's a vegetal parade that reminds us, yet again, how some chunks of Earth's biosphere still smack of terra incognita. Barbara Kiser 